\title{
Sakubitril/valsartan SGLT2 inhibitörleriyle beraber kullanılabilir mi?
}

\author{
Dr. Özlem Yıldırımtürk
}

Sağlık Bilimleri Üniversitesi, Dr. Siyami Ersek Eğitim ve Araştırma Hastanesi, Kardiyoloji Kliniği, İstanbul

2008 yilında EMA ve FDA yeni geliştirilen tüm glikoz-düşürücü ilaçların onay öncesi kardiyovasküler risk değerlendirilmesinden geçmesi gerektiğini belirten bir endüstri kılavuzu yayınlad1. ${ }^{[1]}$ Buna göre kardiyovasküler risk değerlendirmesi amacıyla kardiyovasküler ölüm, ölümcül olmayan miyokard infarktüsü ve inmenin diyabet çalışmalarında değerlendirilmesi gerekmekteydi. Bu risk değerlendirmesi içerisinde kalp yetersizliği (KY) olmamakla birlikte tiazolidinedionlar ve saksagliptin ile yapılan çalışmalar KY sıklığında ve KY nedeniyle hastaneye yatışlarda artmaya yol açmışlardı. Bu sebeplerle yeni geliştirilen Sodyum Glukoz Ko-transporter-2 inhibitörleri (SGLT2i) (empagliflozin, dapagliflozin, kanagliflozin) ile yapılan çalışmalarda KY verileri de değerlendirildi ve KY'ne bağlı hastaneye yatışlarda azalmaya yol açtıkları gösterildi. SGLT2i'lerin KY hastalarında yararı üzerine etki mekanizmalarına yakından bakıldı̆̆ında, glikoz reabsorbsiyonunu engelleyerek glikozüri, natriürez ve diüreze yol açtıkları gösterilmiştir. ${ }^{[2]}$ $\mathrm{Bu}$ ajanların proksimal tubul üzerinden etki göstererek intraglomerüler basıncı azaltması ve intravasküler sıvıdan çok intrasellüler mesafedeki sıvı volümünde azalma sağlamaları en belirleyici özellikleridir. ${ }^{[3]}$

KY tedavisinde en son mortaliteyi azaltan ajan olarak tedaviye eklenen S/V'in SGLT2i'ler ile beraber kullanımı ile ilgili veriler oldukça kısıtlıdır. Empagliflozin ile yapılan EMPA-REG OUTCOME ${ }^{[4]}$ çalışmasında, kanagliflozin ile yapılan CANVAS ${ }^{[5]}$ çalışmasında S/V kullanan hasta sayılarına dair herhangi bir veri bulunmamaktadır. Dapagliflozin ile yapılan DEFINE-HF (Dapagliflozin Effects on Biomarkers, Symptoms, and Functional Status in Patients With Heart Failure With Reduced Ejection Fraction $)^{[6]}$ çalışmasında dahil edilen hastaların \%33'ü S/V kullanmaktaydı. Sadece 263 hastanın alındığı bu randomize çalışmada; hastaların kılavuzlar tarafından önerilen tedaviyi yüksek oranda kullandıkları ve yine $\% 86$ oranında kıvrım diüretiği kullandıkları görülmektedir.
Ancak bu hastaların alt grup analizleri yapılarak her iki ilacı kullanan hastalarda birincil son nokta üzerindeki etkileri değerlendirilmemiştir.

SGLT2 inhibitörlerinden dapagliflozin ile KY hastalarında yapılan ve sonuçları yayınlanan DAPA-HF (Dapagliflozin in Patients with Heart Failure and Reduced Ejection Fraction) çalışmasında da \%10.7'sinin S/V kullandığı belirtilmiştir. ${ }^{[7]}$ Ancak bu çalışmanın sonuçlarında bu hasta alt grubuyla ilgili detaylı veri bulmak mümkün olamamıştır.

Yakın dönemde Docherty ve arkadaşlarının ${ }^{[8]}$ DAPA-HF verilerini kullanarak yaptığı post Hoc analizde; $\mathrm{S} / \mathrm{V}$ tedavisi alan hastaların diğer hastalara göre daha fazla cihaz tedavisi (ICD veya CRT) uyguland1$\breve{g} 1$, ortalama ejeksiyon fraksiyonlarının ve NT-proBNP seviyelerinin daha düşük olduğu gözlenmiştir. Birincil son noktalar ve kardiyovasküler ölüm açısından değerlendirildiğinde; dapagliflozin tüm tedavi alt gruplarında dolayısıyla $\mathrm{S} / \mathrm{V}$ alt grubunda da plaseboya göre yarar sağladığ 1 görülmektedir. $\mathrm{Bu}$ analizle sağlanan veriler, dapagliflozinin kan şekeri düşürme etkisinden bağımsız olarak öne sürülen diüretik etki, renal eritropoetin salınımı, miyokardiyal fibrozisde azalma, adipokinlerde ve sitokin salınımındaki değişiklikler gibi etkileriyle KY hastalarında yarar sağladığını düşündürmektedir. ${ }^{[9]}$ Beta-bloker, MRA ve S/V'a ek olarak dapagliflozin alan \%7'lik küçük hasta grubunda sonuçların plasebo alan hastalara göre daha iyi olduğu gözlenmekle beraber istatistiksel anlamlılığa ulaşmamıştır. Ne Kansas City Cardiomyopathy Questionnaire (KCCQ) Total Symptom Score (TSS)'da ne de kreatinin ve sistolik kan basinci seviyelerinde S/V kullanan hastalarda anlamlı değişiklik saptanmamıştır (Tablo 1). $\mathrm{Bu}$ alt grup analizi bize KY tedavisindeki ana tedaviye eklenen dapagliflozinin yarar sağladığının gösterilmesi açısından önemlidir. Tüm alt grup analizler gibi bu analizde verdiği bilgiler açısından dikkatli olarak ele alınmalıdır. Özellikle S/V kullanan hasta sayısının oldukça az olması bu analizin önemli bir kısıtlılığıdır. 
Tablo 1. DAPA-HF çalışmasında S/V kullanan hastaların alt grup değerlendirilmesi

\begin{tabular}{|c|c|c|c|}
\hline & ARNI Evet $(n=508)$ & ARNI Hayır $(n=4236)$ & İnteraksiyon p değeri \\
\hline \multicolumn{4}{|l|}{ Sistolik kan basıncı } \\
\hline (plaseboya göre düzeltilmiş değişim) & $-1.47(-3.92$ to 0.98$)$ & $-1.41(-2.30$ to -0.51$)$ & 0.50 \\
\hline \multicolumn{4}{|l|}{ Kreatinin } \\
\hline (plaseboya göre düzeltilmiş değişim) & $0.02(-0.03$ to 0.06$)$ & $0.02(0.01$ to 0.04$)$ & 0.45 \\
\hline \multicolumn{4}{|l|}{ Volum kaybı } \\
\hline Dapagliflozin & $27 / 250(10.8)$ & $151 / 2118(7.1)$ & \multirow[t]{2}{*}{0.38} \\
\hline Plasebo & $31 / 258(12.0)$ & $131 / 2110(6.2)$ & \\
\hline \multicolumn{4}{|l|}{ Renal yan etki } \\
\hline Dapagliflozin & $25 / 250(10.0)$ & $128 / 2118(6.0)$ & \multirow{2}{*}{0.59} \\
\hline Plasebo & 25/258 (9.7) & $145 / 2110(6.9)$ & \\
\hline
\end{tabular}

ARNI: Anjiyotensin reseptör neprisilin inhibitörü; *: Eur Heart J. 2020;ehaa183. doi:10.1093/eurheartj/ehaa183'dan modifiye edilmiştir.

KY hastalarında hem SGLT2 inhibitörlerini hem de S/V kullanan hastaların değerlendirilmesi amacıyla dizayn edilen çalışmalar olmaksızın bu konuda net kararlar vermek mümkün değildir.

Elimizdeki veriler, $\mathrm{S} / \mathrm{V}$ kullanan olgularda tedaviye dapagliflozin eklenmesinin ilave klinik yarar sağladığını desteklemektedir. Ancak her 2 ilacında natriürez, diürez, kan basıncında azalma ile ilgili etkilerinin kombine kullanımda potansiyelize olabileceği akılda tutulmalı ve güvenlik açısından 2 ilacın birlikte kullanımı durumunda sistolik kan basıncı ve böbrek fonksiyonlarının (potasyum, GFR, kreatinin) yakından takip edilmesi gerektiği göz önünde bulundurulmalidir.

\section{Kaynaklar}

1. US Food and Drug Administration. Guidance for Industry on Diabetes Mellitus-Evaluating Cardiovascular Risk in New Antidiabetic Therapies to Treat Type 2 Diabetes; Availability. Available at: https://www. federalregister.gov/documents/2008/12/19/E8-30086/guidance-forindustry-on-diabetes-mellitus-evaluating-cardiovascular-risk-innew-antidiabetic Accessed Jul 17, 2020.

2. Çavuşoğlu Y, Altay H, Cahn A, Celik A, Demir S, Kılıçaslan B, et al.
Sodium glucose co-transporter 2 inhibitors in heart failure therapy. Turk Kardiyol Dern Ars 2020;48:330-54.

3. Perkovic V, Jardine MJ, Neal B, Bompoint S, Heerspink HJL, Charytan DM, et al. Canagliflozin and Renal Outcomes in Type 2 Diabetes and Nephropathy. N Engl J Med. 2019;380:2295-306.

4. Fitchett D, Butler J, van de Borne P, Zinman B, Lachin JM, Wanner $\mathrm{C}$, et al. Effects of empagliflozin on risk for cardiovascular death and heart failure hospitalization across the spectrum of heart failure risk in the EMPA-REG OUTCOME® trial. Eur Heart J 2018;39:363-70.

5. Figtree GA, Rådholm K, Barrett TD, Perkovic V, Mahaffey KW, de Zeeuw D, et al. Effects of Canagliflozin on Heart Failure Outcomes Associated With Preserved and Reduced Ejection Fraction in Type 2 Diabetes Mellitus. Circulation 2019;139:2591-3.

6. Nassif ME, Windsor SL, Tang F, Khariton Y, Husain M, Inzucchi SE, et al. Dapagliflozin Effects on Biomarkers, Symptoms, and Functional Status in Patients With Heart Failure With Reduced Ejection Fraction: The DEFINE-HF Trial. Circulation 2019;140:1463-76.

7. McMurray JJV, Solomon SD, Inzucchi SE, Køber L, Kosiborod MN, Martinez FA, et al. Dapagliflozin in Patients with Heart Failure and Reduced Ejection Fraction. N Engl J Med. 2019;381:1995-2008.

8. Docherty KF, Jhund PS, Inzucchi SE, Køber L, Kosiborod MN, Martinez FA, et al. Effects of dapagliflozin in DAPA-HF according to background heart failure therapy. Eur Heart J 2020;41:2379-92.

9. Verma S, McMurray JJV. SGLT2 inhibitors and mechanisms of cardiovascular benefit: a state-of-the-art review. Diabetologia 2018;61:2108-17. 